Journal of History Culture and Art Research (ISSN: 2147-0626)

Tarih Kültür ve Sanat Araştırmaları Dergisi

Revue des Recherches en Histoire Culture et Art

مجلة البحوث التاريخية و الثقافية والفنية
Vol. 7, No. 3, September 2018

Copyright (C) Karabuk University

http://kutaksam.karabuk.edu.tr

\title{
DOI: 10.7596/taksad.v7i3.1526
}

Citation: Sarıköse, B. (2018). XIX. Yüzyıl Sonlarında ve XX. Yüzyıl Başlarında Ermenek'in İdarî Yapısı. Journal of History Culture and Art Research, 700-712. doi:http://dx.doi.org/10.7596/taksad.v7i3.1526

\section{Yüzyıl Sonlarında ve XX. Yüzyıl Başlarında Ermenek'in İdarî Yapısı}

\section{Administration Structure of Ermenek at the end of XIX'th Century and at the Begining of XX'th Century}

Barış Sarıköse ${ }^{1}$

\begin{abstract}
Ermenek which was located in Seljuk in the period of Turkey Seljuk State, took part in the border's of Karamanoğulları Principality after the collapsed fo Turkey Seljuk State. Ermenek and it's surroundings where connected to Ottoman State after Karamanoğulları Principality was ended by Ottoman State. Ermenek took part in İç-il Sanjak of Karaman Principality in the tahrir of 1530 in the period of Sultan Süleyman I. Ermenek has taken Karaman Principality for long centuries. New regulations were done about the administration of province of Ottoman State with 1864 and 1871 regulations in the XIX'th century. In context some new regulations were made about the administration of Ermenek which took part in Iç-il Sanjak of Konya Province. İç-il liva which was connected to Konya Province before was connected to Adana Province. By means of this administration regulations from 1870's to beginning of XX'th centuries. Ermenek stayed connected to Adana Province. In the beginning of XX'th centuries Ermenek was reconnected to Konya Province. District council and municipality council had established depend on this administrative regulations. Thus people had the opportunity to participate in local government. New administrative units had established and a lot of civil servants had employed in this administrative units. Regulations had made in tax, population record, law and land register field according to new administrative of district in Ermenek. Some new administrative regulations had made on villages administrative status in this period. Ermenek's village structure at the end of XIX'th century had created the village's structure in the period of Republic.

In this research administrative regulations which were at the end of XX'th and the beginning of the XX'th century and new civil servants and administration units about administrative structure were according to the archival documents.
\end{abstract}

Keywords: Ermenek, Karaman, Administration structure, XIX'th century, Adana province, Konya province, İç-il Sanjak.

\footnotetext{
${ }^{1}$ Doç. Dr. Karabük Üniversitesi Edebiyat Fakültesi Tarih Bölümü, Türkiye. E-mail: barissarikose@gmail.com
} 
Türkiye Selçuklu Devleti döneminde Selçuklu sınırları içinde yer alan Ermenek, Türkiye Selçuklu Devleti'nin yıkılmasından sonra Karamanoğulları Beyliği sınırları içine girmiştir. Osmanlı Devleti'nin Karamanoğulları Beyliği'ne son vermesi ile Ermenek ve çevresi Osmanlı Devleti'ne bağlanmıştır. Ermenek, Kanuni Sultan Süleyman Dönemi'nde 1530'da yapılan tahrirlerde Karaman Eyaleti İç-il Livası sınırları içinde yer almaktadır. Ermenek, uzun asırlar Karaman Eyaleti sınırları içinde yer almıştır. XIX. yüzyılda Osmanlı Devleti'nin vilayet idaresinde 1864 ve 1871 nizamnâmeleriyle yeni düzenlemeler yapılmıştır. Bu bağlamda Konya Vilayeti İç-il Livası sınırları içinde yer alan Ermenek'in idarî yapısında da birtakım değişiklikler yaşanmıştır. Daha önce Konya Vilayeti'ne bağlı olan İç-il Livası Adana Vilayeti'ne bağlanmıştır. Bu idarî düzenlemeler çerçevesinde Ermenek 1870'li yıllardan XX. yüzyıl başına kadar Adana Vilayeti'ne bağlı kalmıştır. Ermenek, XX. yüzyılın başında tekrar Konya Vilayeti'ne bağlanmıştır. İdarî düzenlemelere bağlı olarak Ermenek'te kaza idare meclisi ve belediye meclisi kurulmuştur. Böylelikle halkın yerel yönetime katılması yönünde önemli bir adım atılmıştır. Bu süreçte Ermenek'te yeni idarî birimler kurulmuş bu birimler de birçok yeni memur istihdam edilmiştir. Ermenek'te vergi, nüfus kaydı, hukuk ve tapu kaydı gibi alanlarda yeni vilayet idaresine göre düzenlemeler yapılmıştır. Bu dönemde Ermenek'e bağı köylerin idarî durumlarında da birtakım idarî değişiklikler yapılmıştır. Ermenek'in XIX. yüzyıldaki köy yapısı Cumhuriyet dönemindeki köy yapısının temellerini oluşturmuştur.

Bu araştırmada Ermenek'in, XIX. yüzyıl sonlarında ve XX. yüzyıl başlarında geçirmiş olduğu idarî değişim ve idarî yapıda ortaya çıkan yeni birim ve memuriyetler arşiv belgelerine göre değerlendirilecektir.

Anahtar Kelimeler: Ermenek, Karaman, İdarî yapı, XIX. Yüzyıl, Adana vilayeti, Konya vilayeti, İç-il Livası.

\section{Giriş}

Anadolu'nun güneyinde Silifke ve Göksu ırmağı çevresine Selçuklular döneminden itibaren içc-il adı verilmiştir. Dağlar içinde girilmesi yerlerin çokluğu ve taşlık sahaların genişliğinden dolayı aynı sahaya Taşili de denmektedir. Günümüzde aynı sahanın adı Taşeli olarak da söylenmektedir (Sarıköse, 2013: 114). Ermenek havalisi I. Alâedin Keykubad (1220-1237) döneminde Kilikya Ermenilerinden fethedilmiştir (Uzunçarşılı, 1998: 43). Türkiye Selçukluları döneminde Ermenek havalisi I. Alâedin Keykubad (1220-1237) döneminde fethedilince valisinin ismine izafeten Ermenek havalisine Kamereddin-ili adı verilmiştir (Turan, 1998: 510). Bölgeye Karamanoğulları'nın elinde uzun yıllar kaldığından dolayı Karamanoğlu Beyi Kerimüddin Bey'den dolayı Kamerüddin ili, Karaman ili şeklinde de isimler verilmiştir (Sarıköse, 2013: 114). Selçukluların başkenti Konya'dan bakıldığında dağ içinde olmasından dolayı Selçuklulardan beri bölgeye iç-il denmiştir (AVS, 1299: 76). Ermenek'in coğrafi sınırlarında Kuzeyde Karaman Kazası'nın Aladağ ve Hadim nahiyeleri, doğusunda Gülnar ve Mut kazaları, güneyden Anamur ve batı tarafında Alanya Kazası yer almaktaydı (KVS, 1332: 176). Daha sonraki yıllarda iç-il adı iç-el şeklinde söylenirken, İç-il ve Mersin'in birleştirilmesiyle oluşturulan vilayete de iç̧el adı verilmiştir. Günümüzde Ermenek ve çevresinin de bu bölge sınırları içinde olduğu anlaşılmaktadır.

Türkiye Selçukluları döneminde Ermenek, Kayseri beldeleri içinde zikredilmektedir (Turan, 1998: 477). Türkiye Selçuklu Sultanı I. Alâeddin Keykubad, 1218'de Ermenek ve havalisini kendi sınıları içine katmış, buraya Türkmen kabilelerini iskân etmiştir. Bunların başına da Kerimeddin Karaman'ı getirmiştir. IV. Kilıçarslan (1249-1254, 1257-1262, 1262-1266) 1256'da Ermenek'i Karaman'a vermiş böylelikle Karamanoğulları́nın bağımsızıklarının temeli atılmıştır. Türkiye Selçuklu Devleti'nin yıkıımasından sonra Ermenek, Karamanoğullarının yurdu haline gelmiştir. Ermenek, Karamanoğulları́nın önemli şehirlerinden biridir (Konyalı, 1997: 57-58, 60). Karamanoğullarının iç mücadelesinde Ermenek ve çevresindeki kaleler önemli sı̆̆ınak noktalarındandı (Aköz- Ürekli, 2006: 79). 
Ermenek ve çevresi Karamanoğulları döneminde büyük bir öneme sahipti burada birçok vakıf da tesis edilmiştir. Karamanoğullarının ilk dönemine ait Ermenek merkezde Ulu Cami bulunmaktadır. Ayrıca Karamanoğlu Mahmud Bey (1300-1311) Ermenilerle yaptığı bir savaştan sonra ölmüş ve Ermenek'e bağlı Balkasun Köyü'ne defnedilmiştir. Emir Musa (1352-1356) vefat edince Ermenek'te Tol Medrese bitişiğindeki türbeye defnedilmiştir (Aköz-Ürekli, 2006: 80, 83). Karamanoğulları beylerinin buraya defnedilmesi ve burada Karamanoğulları döneminde birçok vakıf eserin tesis edilmesi Ermenek'in Karamanoğulları dönemindeki önemini ortaya koymaktadır.

Konya ve çevresi 1467 'de Osmanlı sınırları içine katılmıs, Karaman ili sınırları içinde bulunan Ermenek, 1473'te Gedik Ahmed Paşa tarafından Osmanlı'ya bağlanmıştır (Aköz-Ürekli, 2006: 83). Karaman İli'nde Sultan II. Bayezid (1481-1512) döneminde yapılan tahrirde Karaman Vilayeti 15 kazaya ayrılmıştır. Bu kazalardan biri de Ermenek Kazası'dır (Konyalı, 1997: 114).

\section{Tanzimat Öncesinde Ermenek'in İdarî Yapısı}

Osmanlılar tarafından fethinden sonra Konya ve Karaman çevresi ile Ermenek'in de içinde bulunduğu saha Karaman Eyaleti sınırları içinde yer almışır. 1500-1518 yılları arasında iç-il Livası sınırları içinde Ermenek, Gülnar, Karataş ve Mut olmak üzere dört kaza mevcuttur (Çelik, 2000: 452). Kanuni Sultan Süleyman (15201566) döneminde 1530 'da yapılan tahrirde Karaman Eyaleti sınırları içinde bulunan İç-il Livası'nda Ermenek, Mut, Karataş, Gülnar ve Selendi kazaları yer almaktaydı (BOA, 1996: 32-35). XVI. asırda Ermenek Kazası'nda Mescidlü, Zaviye, Değirmenlik ve Bağ Arası mahalleleri bulunmaktaydı. Gargara, Uğurlu, Paşa Kışlası, i̇skeçe, Cemaller, Lamas, Çavuşlar ve Baklasun gibi önemli köyleri vardı (Tekindağ, 1978: 317).

İç-il Livası sınırları içinde olan Ermenek'e bağıı 1530'da 50 köy bulunmaktadır. 1530'da Ermenek'e bağı köy, mezra ve yaylalar şunlardır (BOA, 1996: 253-265);

Tablo 1: 1530'da Ermenek'e bağılı köy, mezra ve yaylalar

\begin{tabular}{|c|c|c|}
\hline Köyler & Mezralar & Yaylalar \\
\hline 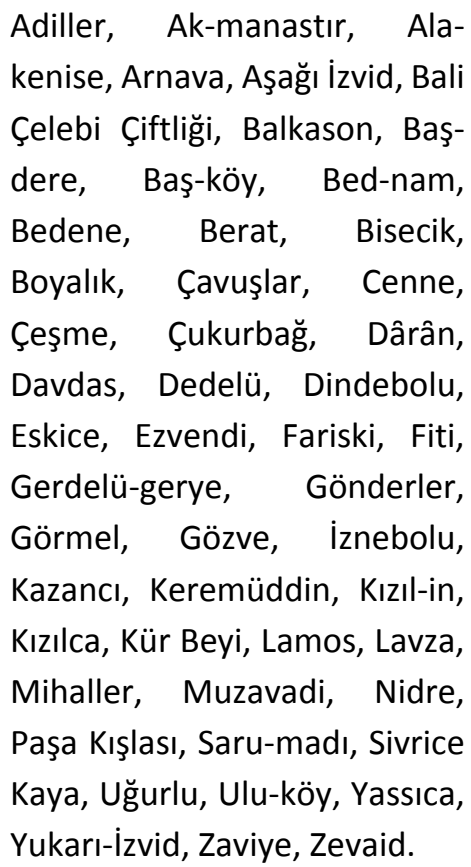 & $\begin{array}{l}\text { Adiller, Ak-depe, Akpınar, } \\
\text { Altuntaş, Bahadır Boğazı, } \\
\text { Baladan Oluğu, Bali Kışlağı, } \\
\text { Belenova, Burun, Bey Pınar, } \\
\text { Çam Depesi, Çömleki Toprağı, } \\
\text { Dağlu-taş, Depe-dayağu, } \\
\text { Düğünözü, Furun-oluk, Göçük, } \\
\text { Koşu Damı, Kör Sinan Gedüğü, } \\
\text { Kurutaş, Kuruca, Kuyucak, } \\
\text { Mazya-seniri, Mengen Alanı, } \\
\text { Narluca, Söğüt, Şahinler, } \\
\text { Taşluca-oluk, Yarenlüce, } \\
\text { Yazıbey, Yeğanca, Yolkaya, } \\
\text { Zengi. }\end{array}$ & $\begin{array}{l}\text { Ala-kenise, Ali Fakih Gedüğü, } \\
\text { Göl-yeri, Gölcük, Halil, Hatun } \\
\text { Ekinliği, Kâfir Alanı, Karakaya, } \\
\text { Kebiş Bucağı, Kesil-eni, Keçilü, } \\
\text { Kızılkaya, Yol Kaya. }\end{array}$ \\
\hline
\end{tabular}


İç-il Sancağı, Osmanlı döneminde ilk kuruluşundan Kıbrıs'ın fethine kadar Karaman Beylerbeyliği sınırları içinde kalmıştır. Kıbrıs'ın 1571'de fethinden sonra Alaiye, Sis ve Tarsus sancakları ile beraber Kıbrıs Beylerbeyliği'ne bağlanmıştır (Bilgili, 2001: 35). 1608'de daha önce Halep sınırları içinde bulunan Adana müstakil bir eyalet haline getirilmiştir. Bu tarihte Kıbrıs'a bağıı olan İç-il livası da Adana’ya bağlanmıştır (Kılıç, 1999: 95). 1632'de sancak Adana Vilayeti'ne bağlanmışsa da aynı yıl içinde tekrar Kıbrıs'a bağlanmıştır. XVIIXVIII. yüzyıl itibarıyla İçel Sancağı Adana Vilayeti sınırları içindedir. (Gazel, 2016: 22).

\section{Tanzimat Sonrasında Ermenek'in İdarî Yapısı}

Osmanlı'nın idarî yapısı kuruluştan itibaren eyalet şeklinde tanzim edilirken XIX. yüzyılla birlikte vilayet şeklinde düzenleme yapılmıştır. Ermenek'in bağlı olduğu İç-il Livası 1831'de Adana vilayet sınırları içindedir (Karpat, 2003: 52). İç-il Sancağı XIX. yüzyıl başlarına kadar genel olarak Adana Vilayeti'ne bağlı kalmıştır. Ancak bazen kısa süreli olarak da Konya'ya bağlandığı görülmektedir. Mesela, 1836'da İç-il sancağı Konya Müşirliği'ne bağlanmış eyalet sistemine geri dönülmesiyle birlikte Karaman Eyaleti'ne bağlanmıştır (Gazel, 2016: 227). 1851-1852'de İç-il Sancağı tekrar Adana Vilayeti'ne bağlanmıştır. 1853'te i̇ç-il Sancağı tekrar Karaman'a bağlanmıştır (Gazel, 2016: 227). İç-il Sancağı́'nın merkezi genel olarak Silifke'dir. Ancak kısa süreli olarak Ermenek'in de sancak merkezi olduğu bilinmektedir. 1867'den itibaren iç-il Livası, Konya'dan ayrılarak Adana Vilayeti'ne bağlanmıştır (Çadırcı, 1997: 368). 1868-1870'te Konya Vilayeti'ne bağlı olan İç-il Livası'nın mutasarrıflık merkezi Ermenek'tir. Bu yıllarda Ermenek sınırları çcinde Nevahi adı ıir nahiye yer almaktadır. Bu tarihten itibaren kısa süreli tekrar Konya Vilayeti sınırları içinde görülen Ermenek 18811893'te Adana Vilayeti içc-il Sancağı içinde Silifke, Mut, Gülnar ve Anamur dışındaki bir diğer kazadır (Sarıköse, 2013: 114-115). 1872'den 1903 yılına kadar Ermenek, Adana Vilayeti, İç-il Sancağı́na bağlı kazalardan biridir. Bu yıllarda iç- il Sancağı içinde Silifke, Anamur, Gülnar ve Mut kazaları da yer almaktadır. (Sarıköse, 2016: 556-557).

Ermenek'in 1869 yılına kadar iç-il Sancağı'nın merkezi olması, aynı yıl içinde sancağın Adana'ya bağlanmasıyla sancak merkezinin Silifke olmasından dolayı Silifkeliler ile Ermenekliler arasında sancak merkezi olmak amacıyla tartışmaların da başlamasına sebep olmuş Ermenekliler, sancak merkezinin tekrar Ermenek yapılarak sancağın Konya'ya bağlanmasını talep etmişlerdir. Silifkeliler de sancak merkezinin Silifke'de kalması için başvuruda bulunmuşlardır (Gazel, 2016: 228-229). Ermenekliler ile Silifkeliler arasındaki kaza merkezinin Ermenek olması ve Konya vilayetine bağlanma yönündeki tartışmalar, $1878^{\prime}$ de Ermenek halkının talebi Sadaret'e yazması ile tartışma merkeze taşınmış, merkez bu talebe ilk önce olumlu yaklaşmışsa da kaza merkezinin Silifke olması ve bağılığın Adana Vilayeti'ne devam etmesine karar verilmiştir. (Gazel, 2016: 231). 1902'de Ermenek'in kaza merkezi olup, Konya'ya bağlanma talebi yeniden gündeme gelmiş, yapılan yazışmalara ve Ermeneklilerin talebine rağmen Ermenek'in sahilden uzak olması, Silifke'nin kaza merkezi olmasının güvenlik ve ticaret açısından yerinde olacağı gibi sebeplerle talep yine kabul görmemiştir (Gazel, 2016: 233, 240). 1904 yılında başlayan Ermenek'in Konya'ya bağlanma tartışmaları 1906 yılııın Ocak-Şubat ayında Ermenek'in Konya'ya bağlanması ile neticelenmiştir. (Gazel, 2016: 258). 1915'te Konya'ya bağlı Ermenek Kazası yakın olmasından dolayı tekrar İçel Sancağı'na bağlanmıştır. 7 Mart 1915 tarihi ile Ermenek, İçel Sancağı'na ilhak edilmiştir (Gazel, 2016: 260). 1915 yılında iç-il, Adana Vilayeti'ne bağlı müstakil bir sancak haline getirilmiştir. 1924'te İçel Sancağı İçel Vilayeti haline getirilmiş ve vilayet merkezi Silifke olmuştur (Gazel, 2016: 227). Ermenek kaza olarak kısa süreli 19041905'te Adana Vilayeti'nden ayrılarak Konya Vilayeti'ne bağlanmıştır (KVS, 1322: 81-84, 289).

Ermenek Kazası'nın idaresinde 1864 ve 1871 Vilayet Nizamnamelerine göre kaymakam, naib, müftü, mal müdürü ve sandık emini gibi idareciler görevlendirilmiştir. 1872-1906 yılları arasında Ermenek Kazası'na düzenli olarak idarecilerin tayin edildiği anlaşılmaktadır (AVS, 1289: 106; AVS, 1290: 102; AVS, 1293: 126; AVS, 1294: 123; AVS, 1296: 189; AVS, 1297: 117; AVS, 1299: 78; AVS, 1308: 121; AVS, 1309: 129; AVS, 1312: 192; AVS, 1318: 214; AVS, 1320: 214; KVS, 1322: 81). 
Tablo 2: Ermenek'in 1872-1906 Yılları Arasındaki İdarecileri

\begin{tabular}{|c|c|c|c|c|c|}
\hline Yıl & Kaymakam & Naib & Müftü & Mal Müdürü & $\begin{array}{l}\text { Sandık } \\
\text { Emini }\end{array}$ \\
\hline $\begin{array}{l}1872- \\
1873\end{array}$ & Arslan Bey & $\begin{array}{l}\text { Hüseyin Şükrü } \\
\text { Efendi }\end{array}$ & Emin Efendi & Ahmed Bey & $\begin{array}{l}\text { Ibrahim } \\
\text { Edhem } \\
\text { Efendi }\end{array}$ \\
\hline $\begin{array}{l}1873- \\
1874\end{array}$ & $\begin{array}{l}\text { Mehmed Sabri } \\
\text { Efendi }\end{array}$ & $\begin{array}{l}\text { Hüseyin Şükrü } \\
\text { Efendi }\end{array}$ & Emin Efendi & Ali Rıza Efendi & $\begin{array}{l}\text { Mustafa } \\
\text { Edib Efendi }\end{array}$ \\
\hline 1876 & $\begin{array}{l}\text { Osman Efendi } \\
\text { Efendi }\end{array}$ & Abdurrauf Efendi & $\begin{array}{l}\text { Mehmed Emin } \\
\text { Efendi }\end{array}$ & Ali Rıza Efendi & \\
\hline 1877 & $\begin{array}{l}\text { Mehmed Raşid } \\
\text { Efendi }\end{array}$ & $\begin{array}{l}\text { İbrahim Kâmil } \\
\text { Efendi }\end{array}$ & $\begin{array}{l}\text { Mehmed Emin } \\
\text { Efendi }\end{array}$ & Ali Rıza & \\
\hline $\begin{array}{l}1878- \\
1879\end{array}$ & $\begin{array}{l}\text { Mehmed Raşid } \\
\text { Efendi }\end{array}$ & Ali Rıza Efendi & $\begin{array}{l}\text { Mehmed Emin } \\
\text { Efendi }\end{array}$ & Ali Rıza Efendi & $\begin{array}{l}\text { Hafız } \\
\text { Hüseyin } \\
\text { Efendi }\end{array}$ \\
\hline $\begin{array}{l}1879- \\
1880\end{array}$ & $\begin{array}{l}\text { Mehmed Raşid } \\
\text { Efendi }\end{array}$ & Ali Rıza Efendi & $\begin{array}{l}\text { Mehmed Emin } \\
\text { Efendi }\end{array}$ & $\begin{array}{l}\text { Mehmed Nafiz } \\
\text { Bey }\end{array}$ & \\
\hline $\begin{array}{l}1881- \\
1882\end{array}$ & Nafiz Efendi & -- & $\begin{array}{l}\text { Mehmed } \\
\text { Efendi }\end{array}$ & Haydar Efendi & \\
\hline $\begin{array}{l}1890- \\
1891\end{array}$ & $\begin{array}{l}\text { Yusuf Ziyaeddin } \\
\text { Efendi }\end{array}$ & $\begin{array}{l}\text { Abdurrahman Hilmi } \\
\text { Efendi }\end{array}$ & $\begin{array}{l}\text { Mehmed Ayni } \\
\text { Efendi }\end{array}$ & Recep Efendi & \\
\hline $\begin{array}{l}1891- \\
1892\end{array}$ & İzzet Bey & $\begin{array}{l}\text { Abdurrahman Hilmi } \\
\text { Efendi }\end{array}$ & $\begin{array}{l}\text { Mehmed Ayni } \\
\text { Efendi }\end{array}$ & Recep Efendi & \\
\hline $\begin{array}{l}1894- \\
1895\end{array}$ & $\begin{array}{l}\text { Mehmed Hulusi } \\
\text { Efendi }\end{array}$ & $\begin{array}{l}\text { Mehmed Şefik } \\
\text { Efendi }\end{array}$ & $\begin{array}{l}\text { Mehmed Ayni } \\
\text { Efendi }\end{array}$ & $\begin{array}{l}\text { Hüseyin Hüsnü } \\
\text { Efendi }\end{array}$ & \\
\hline $\begin{array}{l}1897- \\
1898\end{array}$ & $\begin{array}{l}\text { Mehmed } \\
\text { Selahaddin } \\
\text { Efendi }\end{array}$ & Ahmed Kâmil & Ahmed Naci & Ahmed Efendi & \\
\hline $\begin{array}{l}1902- \\
1903\end{array}$ & $\begin{array}{l}\text { Mehmed } \\
\text { Selahaddin } \\
\text { Efendi }\end{array}$ & $\begin{array}{l}\text { Ahmed Kâmil } \\
\text { Efendi }\end{array}$ & $\begin{array}{l}\text { Ahmed Naci } \\
\text { Efendi }\end{array}$ & $\begin{array}{l}\text { Hâfız Mustafa } \\
\text { Efendi }\end{array}$ & \\
\hline 1906 & $\begin{array}{l}\text { Mehmed Nazif } \\
\text { Bey }\end{array}$ & Abdülhalim Efendi & $\begin{array}{l}\text { Ahmed Naci } \\
\text { Efendi }\end{array}$ & $\begin{array}{l}\text { Mehmed Emin } \\
\text { Efendi }\end{array}$ & \\
\hline
\end{tabular}


Ermenek'te kaza idarecileri yanında kısa sürede birçok yeni memuriyet de ihdas edilmiştir. 1873-1874'te Tahrirat Kâtibi Mustafa Fahri Efendi, Vukuat Kâtibi Abdi Efendi'dir (AVS, 1290: 102). 1891-1895'te Nuri Efendi (AVS, 1308: 129; AVS, 1312: 192), 1900-1906'da Mustafa Nazif Efendi Ermenek Tahrirat kâtibidir (AVS, 1318: 294; AVS, 1320: 214; KVS, 1322: 81).

Osmanlı'da XIX. yüzyılda vilayetlerin altında kazalarda kaymakam başkanlığında kaza idare meclisleri kurulmuştur. Kaymakam başkanlığındaki kaza idare meclisinde mal müdürü, tahrirat kâtibi, naib, müftü, gayr-i Müslim cemaat reisleri, iki Müslim ve iki gayr-i Müslim seçilmiş üye yer almaktaydı (Ortaylı, 2000: 80,82). Ermenek'in kaza idare meclisi de XIX. yüzyıl sonunda düzenli olarak teşkil edilmiştir. 1872-1873'te Ermenek Meclis-i İdare-i Kaza'sında kaymakam, naib, müftü ve mal müdürü gibi atanmış üyeler yanında Ahmed Efendi, Mehmed Hilmi Efendi, Mehmed Efendi ve Ali Rıza Efendi gibi seçilmiş üyeler görev almıştır. Kaza idare meclisinde bir kâtip de istihdam edilmiştir. 1872-1873'te Kaza idare Meclisi kâtibi Abidin Efendi'dir (AVS, 1289: 106). 1873-1874'te Kaza İdare Meclisi üyeleri içinde Tahrirat Kâtibi de yer almaya başlamıştır. Meclisin üyelerinin büyük çoğunluğu aynen devam etmiştir (AVS, 1290: 102). Daha sonraki yıllarda Kaza İdare Meclisi'nin düzenli olarak teşkil edildiği anlaşılmaktadır. 1876-1877'de mecliste Ahmed Efendi, Osman Efendi ve Hüseyin Efendi üye iken Tahrirat Kâtibi Mustafa Fahri Efendi'dir (AVS, 1293: 126; AVS, 1294: 123; AVS, 1296: 189).1879-1880'de meclisin Tahrirat Kâtibi Şevket Efendi, üyeler; Hacı Said Efendi, Hacı Hüsameddin Efendi ve Osman Ağa'dır (AVS, 1297: 117-118). Tahrirat Kâtibi 1881-1882 Kâmil Efendi (AVS, 1299: 78), 1890-1891'de Nuri Efendi'dir (AVS, 1308: 121). 1890-1891'de kaza idaresinde Hacı Ali Efendi zâde Hacı Ahmed, Hacı İbrahim Efendi zâde Rıza Efendi, Hacı Burhan zâde Hacı Mehmed Efendi idare meclisinin seçilmiş üyeleridir (AVS, 1308: 121). 1891-1892'de mecliste iki yeni üye Hacı Said Efendi ve Hacı Hasan Ağa'dır (AVS, 1309: 129). 1894-1895'te idare meclisinin üyeleri değişmiştir. Hacı Ahmed Efendi, Hacı Emin Efendi, Reşid Efendi üye iken meclis kâtibi Nuri Efendi'dir (AVS, 1312: 192). Kaza idare meclisinin XX. yüzyıl başlarında da Ermenek'in idaresinde etkili olduğu görülmektedir. 1900-1901'de kaza idare meclisinde Kacaman zâde Bekir Efendi, Kâmil Efendi, Osman Efendi ve Hulusi Efendi (AVS, 1318: 215), 19021903'te Hacı Sofu zâde Hacı Hâfız Efendi, Hoca zâde Kâmil ve Hacı Reşid üye olarak görev yapmaktadır (AVS, 1320: 214). 1906'da Müftü zâde Mehmed Reşid Efendi, Hacı Süleyman Ağa zâde Hacı Reşid Efendi, Hacı Haydar Efendi ve Nazif Bey zâde Mehmed Remzi Efendi Kaza İdare Meclisi'nin üyeleridir (KVS, 1322: 81). XIX. yüzyıl sonlarından XX. yüzyıl başlarına kadar Ermenek Kaza Idare Meclisi'nde seçilmiş üyelerinin tamamının Müslüman olması Ermenek'te XIX. yüzyıl sonlarında çok fazla gayr-i Müslim yaşamadığının göstergesidir. Bu dönemde az sayıda bir gayr-i Müslim nüfus burada yaşarken XX. yüzyıl başı itibarıyla gayri Müslim nüfus tamamen başka yerlere göç etmiştir.

Ermenek Kazası'na 1872-1873'te Ermenek merkez ve Nevahi adında iki nahiye bağlı olup kaza sınırları içinde 64 köy bulunmaktadır. Kaza merkezi olan Ermenek'in beş mahallesi mevcuttur. Aynı zamanda iç -il Redif Taburu'nun da merkezi Ermenek'tir. Kazada 2.509 hanede 11.628 kişilik bir nüfus yaşamaktadır (AVS, 1289: 107-108). 1873-1874'te Ermenek'e bağı 58 mahalle ve köy bulunmaktadır (AVS, 1290: 143).

Ermenek'e bağlı Nevahi Nahiyesi'ne de düzenli olarak nahiye müdürleri atanmıştır. 1873-1874'te Nevahi Nahiyesi müdürü Ahmed Hilmi Efendi'dir (AVS, 1290: 102). 1876-1877'de nahiye müdürü Mustafa Efendi iken nahiyede kâtip Ahmed Efendi'dir (AVS, 1293: 127; AVS, 1294: 124). 1878-1879'da nahiye müdürü ibrahim Efendi olurken kâtip değişmemiştir (AVS, 1296: 190). 1879-1880'de Nahiye müdürü Mustafa Hulusi Efendi, iken kâtip Ahmed Efendi'dir (AVS, 1297: 121). 1891-1892'de Nevahi müdürü İbrahim Efendi (AVS, 1309: 132), 1900-1903'te nahiye müdürü Mehmed Salih Efendi, Mal kâtibi Adil Efendi'dir (AVS, 1318: 217; AVS, 1320: 217), 1906'da nahiye müdürü Ahmed Salih Efendi, kâtip Selahaddin Efendi'dir (KVS, 1322: 84).

Osmanlı idarî sisteminde 1871 Vilayet Nizamnamesi ile birlikte taşrada belediye idareleri oluşturulmuştur. Belediye meclisi reis ve seçilen altı üyeden oluşmaktaydı. Üyeler iki senede bir seçimle iş başına gelmekteydi (Ortaylı, 2000: 175-176). Osmanlı taşrasındaki genel uygulamaya göre Ermenek'te de belediye meclisinin teşkil edildiği anlaşılmaktadır. Ermenek Belediyesi Ermenek'in idari hayatında 1873-1874'te Belediye Meclisi 
olarak ortaya çıkmıştır. 1873-1874'te Ermenek Belediye Meclisi; Reis Hacı Hüsameddin Ağa, üyeler; Hacı Said Ağa, Mehmed Efendi, Hacı Abdullah Ağa, Kâtip ve Sandık Emini Hacı Abidin Efendi'dir (AVS, 1290: 103). 1876-1877'de belediye meclisi, reis Ömer Faiz Ağa, üyeler; Hacı Mehmed Ağa, Mehmed Efendi, Ahmed Efendi ve Hasan Efendi ile kâtip Ali Efendi'den oluşmaktaydı (AVS, 1293: 127; AVS, 1294: 124). 1878-1880'de belediye reisi Ahmed Bey olurken meclis üyeleri değişmemiştir (AVS, 1296: 190; AVS, 1297: 119). 18811882 'de Hacı Ahmed Efendi belediye reisi iken İbrahim Efendi, Osman Ağa, Hacı Mustafa Ağa ve Hacı Metin Ağa üyedir. Belediye meclisi kâtibi Kâmil Efendi'dir (AVS, 1299: 79). 1890-1891'de Belediye reisi Hacı Hasib Efendi, üyeler Osman Ağa, diğer Hacı Osman Ağa, Hacı Ali Ağa, Hacı Mehmed Efendi'dir. Aynı yıl içinde bir belediye kolcusunun da görev yaptığı anlaşılmaktadır (AVS, 1308: 122). 1891-1892'de belediye meclisi; belediye reisi Rıza Efendi, üyeler; Kâmil Efendi, Osman Ağa, Hacı Abdullah Ağa, Hacı Mehmed Efendi ve Rıza Efendi'den oluşmaktaydı. Belediye kolcusu görevine devam etmekteydi (AVS, 1309: 131). 1894-1895'te belediye reisi değişmezken üyelerden Rıza Efendi yerine Hacı Hâfız Efendi yeni üye olmuştur (AVS, 1312: 194).

XX. yüzyıl başında da belediye meclisinin teşkiline devam edilmiştir. 1900-1903'te belediye reisi Reşid Efendi, üyeler; Hacı Mehmed Efendi, Feyzi Efendi, Mehmed Efendi, Hacı Hafız Efendi ve Hacı Hasan Efendi'dir (AVS, 1318: 216; AVS, 1320: 215). 1906'da reis Ziyaeddin zâde Osman Efendi, üyeler; Hacı Sofu zâde Reşid Efendi, Hacı Hâfız Efendi, Ali Ağa zâde Hacı Efendi, Vasfi Efendi, Numan Efendi zâde Mehmed Efendi, Kâtip Ali Rüstem Efendi'dir (KVS, 1322: 83).

Osmanlı klasik döneminde Kadı mahkemeleri de denilen Şer'iyye Mahkemeleri XIX. yüzyılda da devam etmekteydi. Ancak Şer'i mahkemelerin görev ve yetki alanları XIX. yüzyılda sınırlanmıştı. Bu mahkemeler daha çok evlenme, boşanma, miras ve benzer konuları çözen bir mahkeme haline gelmişti (Çadırcı, 1997: 282). Ermenek Şer'iyye Mahkemesi'nde kâtip Ali Efendi (AVS, 1308: 122; AVS, 1309: 130), 1894-1895'te kâtip Muhiddin Efendi'dir (AVS, 1312: 193).

Osmanlı hukuk sisteminde XIX. yüzyılda basit davaların görülmesi için kaza merkezlerinde Meclis-i Deaviler kurulmaya başlanmıştır (Çadırcı, 1997: 281). 1872-1873'te Ermenek'te Meclis-i Deavi oluşturulmuştur. Meclis-i Deavi, naib efendinin başkanlığında Hacı Abdülmümin, İbrahim Efendi ve Maviş Ağa üyedir. Deavi Meclisi'nin kâtibi Ahmed Efendi'dir. (AVS, 1289: 106). 1873-1874'te meclisin kâtibi Ahmed Kâmil Efendi'dir (AVS, 1290: 102). 1876-1879'da Deavi Meclisi'nde Abdullah Efendi, Mehmed Emin Efendi, Mehmed Said Efendi üye iken kâtip Ahmed Kâmil Efendi'dir (AVS, 1293: 126; AVS, 1296: 189). 1877'de meclise yeni üye olarak Mehmed Said Efendi girmiştir (AVS, 1294: 123).

Osmanlı Devleti'nin XIX. yüzyılda batılı devletlerle olan ticarî ilişkileri ticarî alandaki davalar için yeni düzenlemeleri de zorunlu hale getirmişti. Bu bağlamda Ticaret Mahkemeleri kurulmaya başlandı. 1861'den sonra hızlı bir şekilde Ticaret Mahkemeleri taşrada yaygınlaşmaya başladı (Çadırcı, 1997: 280). Ermenek'te hukuki alanda ortaya çıkan bir diğer kurum Ticaret Mahkemesi'dir (AVS, 1290:102). 1873-1879'da Ermenek Ticaret Mahkemesi'nde başkan Osman Kâmil Efendi iken üyeler; Hacı Süleyman Ağa, Agop Ağa, İsmail Efendi, Osman Efendi, Mehmed Efendi, Serkis Efendi'dir. Meclisin kâtibi Hüseyin Efendi'dir (AVS, 1290: 103; AVS, 1296: 190). Ticaret Mahkemesi üyeleri içinde Agop ve Serkis adlı iki gayr-i Müslim'in bulunması aynı zamanda gayr-i Müslimlerin Ermenek'in ticari hayatında etkinliklerinin de bir kanıtıdır. 1876'da başkan aynı kişi olup değişmezken üyeler arasında diğer Mehmed Efendi, Serkis Efendi yerine ise Nazar Ağa yeni üye olmuşlardır (AVS, 1293: 127). 1877' de gayr-i Müslim olarak sadece Artin Ağa bulunmaktadır (AVS, 1294: 124). Ticaret Meclisi'ndeki gayr-i Müslim üyelerin sayısının azalması XIX. yüzyıl sonlarında gayr-i Müslimlerin Ermenek'in ticari hayatındaki etkinliğini kaybettiklerinin de bir göstergesidir.

Ermenek'te hukuk alanında Bidayet Mahkemesi de kurulmuştur. 1879-1880'de Bidayet Mahkemesi'nde reis naib efendi iken üyeler; Abdullah Efendi, Said Efendi ve Mehmed Emin Efendi'dir. Mahkemede baş kâtip Ahmed Kâmil Efendi, Müstantık Muavini Fahri Efendi, i̇kinci Kâtip Ömer Bahri Efendi'dir. İcra Mübaşiri Ziver 
Efendi ve Hacı Mustafa Ağa, odacı Edhem Ağa'dır (AVS, 1297: 118). 1881-1882'de Bidayet Mahkemesi üyeleri; Osman Efendi, Hacı Mehmed Efendi, baş kâtip Ahmed Kâmil Efendi, Zabıta Kâtibi Ömer Bahir Efendi, Müstantık Muavini Fahri Efendi, Mübaşir Ziver Efendi ve Hacı Mustafa Efendi'dir (AVS, 1299: 78). 18901891'de Bidayet Mahkemesi'nde Ziyaeddin zâde Osman Efendi, Müftü zâde Mehmed Reşid Efendi, baş kâtip Ahmed Kâmil Efendi, ikinci Kâtip Ali Rıza Efendi, Müstantık Kâmil Efendi ve bir mübaşir bulunmaktadır (AVS, 1308: 122). 1891-1892'de mahkeme üyeleri değişmezken mübaşir sayısı iki olmuştur (AVS, 1309: 130). 1894-1895'te Kâmil ve Said Efendi üye iken Baş kâtip Ahmed Efendi, ikinci Kâtip Ali Rıza Efendi, Müstantık muavini Kâmil Efendi ve iki mübaşir bulunmaktadır (AVS, 1312: 193-194). 1900-1901'de üye; Süleyman Lutfi Efendi ve Said Efendi iken Baş kâtip Ahmed Efendi, ikinci Kâtip Ali Rıza Efendi, Müstantık muavini Kâmil Efendi, Şer'iyye Kâtibi Ali Efendi olup, iki de mübaşir vardır (AVS, 1318: 215). 1902-1903'te üye Süleyman Lütfi Efendi, Bekir Efendi, i̇kinci Kâtip Ali Rıza, Müstantık Muavini Abdullah Efendi, Şer'iyye kâtibi Ali Efendi'dir. İki de mübaşir vardır (AVS, 1320: 214). 1906'da Kâmil Efendi ve Hacı Hâfız Efendi üye, Baş kâtip Mehmed Kâmil, ikinci Kâtip Ahmed Efendi, Müstantık Muavini Rıza Efendi, Şer'iyye Katibi Ali Efendi'dir (KVS, 1322: 81).

Ermenek'te 1879-1880'de Tahrir İdaresi adında yeni bir birim oluşmuştur. Bu birimde Vukuat Kâtibi Şevki Efendi iken komisyonda, Ahmed Bey, Abdi Efendi, Hacı Metin Ağa, Artin Ağa, Osman Efendi ve Mehmed Efendi üyedir (AVS, 1297: 119).

Ermenek'te 1873-1874'te Menafi Sandığı kurulmuştur. 1873-1874'te Ermenek Menafi Sandığı Vekilleri; Hacı Abdullah Ağa, Hacı Ali Ağa, Hüseyin Efendi iken kâtip Hüseyin Efendi'dir (AVS, 1290: 103). 1876-1880'de Menafi Sandığı Heyeti; Hacı Abdullah Ağa ve Hacı Abidin Ağa'dan oluşmaktadır (AVS, 1293: 127; AVS, 1296: 190; AVS, 1297: 119). 1877'de sandığa kâtip olarak Ahmed Vasfi Efendi başlamıştır (AVS, 1294: 124). 18811882'de Menafi Sandığı Komisyonu Nuri Efendi, Hacı Abdullah Ağa ve Ahmed Efendi'den oluşmaktaydı (AVS, 1299: 79).

Ermenek'te 1876'da Emlâk İdaresi oluşturulmuştur. Emlâk İdaresi'nde; Abdi Efendi, Hacı Abdülbaki Efendi, Hacı Hüseyin Efendi, Artin Ağa, Ahmed Bey, Osman Efendi ve Mehmed Efendi üye iken vukuat kâtibi Abdi Efendi'dir (AVS, 1293: 126). 1877'de Vukuat Kâtibi Abdi Efendi üyeler; Osman Efendi, Mehmed Efendi, Hacı Metin Ağa ve Artin Ağa'dır (AVS, 1294: 123, AVS, 1296: 190).

Ermenek'in idari yapısındaki görevlilerin sayısında 1876 yılında önemli bir artış meydana gelmiş bu yıl içinde Ermenek'te yeni memurlar ve idareciler görevlendirilmiştir. 1876'da Ermenek Tapu Kâtibi Mustafa Edib Efendi, Nevahi Nahiyesi Tapu Kâtibi Ahmed Bican Efendi, Sandık Emini ibrahim Edhem, nüfus mukayyidi Ali Efendi görevlendirilmiştir (AVS, 1293: 127). 1876 yılı itibarıyla Ermenek'te tapu ve nüfus işleri için memurlukların ortaya çıktığı anlaşılmaktadır. 1877'de Nevahi Nahiyesi Tapu Kâtibi Hâfız Ahmed Efendi (AVS, 1294: 124), 1879-1880 Süleyman Efendi'dir (AVS, 1297: 121). Nüfus İdaresi'nde 1890-1895'te memur Hacı Süleyman iken kâtip Mehmed Nuri Efendi'dir (AVS, 1308: 122; AVS, 1309: 130; AVS, 1312: 193). 19001903'te Memur Hasan Sami Efendi, kâtip Abdülkerim Efendi'dir (AVS, 1318: 216; AVS, 1320: 215), 1906'da Memur ibrahim Fehmi Efendi, kâtip Abdülkerim Efendi'dir (KVS, 1322: 81).

Ermenek'te 1878-1879'da Orman Memurluğu da oluşturulmuş Kâmil Efendi Orman Memuru olarak atanmıştır (AVS, 1296: 191). 1879-1880'de Orman memuru Kâmil Efendi görevine devam etmektedir (AVS, 1297: 121). Ermenek ve çevresinin dağlık ve ormanlık olması burada orman memurluğunun teşkil edilmesindeki en önemli etkenlerdendir. 1894-1895'te Orman Idaresinde Memur Hacı Hasan, piyade korucusu Eyub Ağa'dır (AVS, 1312: 196). 1900-1901'de Orman memuru Vezir Efendi'dir (AVS, 1318: 217). 1902-1903 yılı kaydında Vezir Efendi Orman Korucusu şeklinde kaydedilmiştir (AVS, 1320: 216). 1906'da Orman Avadanlık Memuru Hâfız Efendi'dir (KVS, 1322: 82).

Ermenek'te arazi kayıt işlemleri ve malî konular için de yeni birimler oluşturulmuştur. 1881-1882'de Tapu Kâtibi Mustafa Efendi, Vukuat Kâtibi Şevki Efendi'dir (AVS, 1299: 78). 1891-1892'de Tapu Kaleminde Tapu 
Kâtibi Mustafa Efendi, Yoklama Kâtibi Ömer Efendi ve Kâmil Efendi'dir (AVS, 1309: 131). 1890-1892' de Mal Kalemi'nde Mal Müdürü Recep Efendi, muavini Şevki Efendi, Sandık Emini Hasan Tahsin Efendi, Tapu Kâtibi Mustafa Efendi, Yoklama Kâtibi Mehmed Efendi ve Ömer Efendi'dir (AVS, 1308: 122; AVS, 1309: 130). 18911892'de Nahiye mal kâtibi Mehmed Cevdet Efendi'dir (AVS, 1309: 130). 1894-1895'te Yoklama Kâtibi Ömer Efendi, Mal Müdürü Hüseyin Hüsnü Efendi, muavini Tahir Efendi, sandık emini Mehmed Ali Efendi, nahiye mal kâtibi Mehmed Cevdet Efendi'dir (AVS, 1312: 193-194). 1906'da Mal müdürü Mehmed Emin Efendi, muavini İbrahim Efendi, Sandık Emini Nuri Efendi, Tapu Kâtibi Kâmil Efendi ve Tahsil Memuru olarak ibrahim Efendi görev yapmaktadır (KVS, 1322: 81). 1900-1903'te Mal Kaleminde Mal müdürü Hâfız Mustafa Efendi, Mal Müdürü muavini Remzi Bey, Sandık emini Mehmed Nuri Efendi, Tapu kâtibi Mustafa Efendi'dir (AVS, 1318: 214-215; AVS, 1320: 215).

Vergi tahsili ile ilgili olarak rüsumat memurluğu da Ermenek'te kurulmuştur. 1881-1882'de Ermenek Rüsumat memurluğu oluşturulmuş, Rüsumat memuru Halil Efendi göreve başlamıştır (AVS, 1299: 79).

Osmanlı Devleti'nin yabancı ülkelerden aldığı borçları ödeyememesi üzerine Düyûn-ı Umûmiye ve Reji idareleri kurulmuştu. Taşrada da zamanla bu idarelerin memurları ve temsilcileri görevlendirilmişti. Ermenek'te de Reji idaresi kurulmuştur. Reji Idaresi'nin 1891-1895'te memuru Ahmed Bey, kâtibi ise Rıza Bey'dir (AVS, 1309; AVS, 1312: 196). 1900-1901'de Reji dairesinde Memur vekili Agop Efendi (AVS, 1318: 217), 1902-1903'te memur Hâfız Mehmed Efendi'dir (AVS, 1320: 216). 1906'da Reji memuru Hâfız Efendi'dir (KVS, 1322: 82).

Osmanlı döneminde 1855 yılı itibarıyla telgraf hatlarının Edirne-İstanbul, Edirne Şumnu arasında döşenmesinden sonra kısa sürede taşrada telgraf hatlarının döşenmeye başlandığı bilinmektedir. 1876 yılına kadar artık devlet sınırları içinde her tarafla telgrafla haberleşmek mümkün hale gelmişti. Posta ve Telgraf idaresi 1872'den itibaren birleştirilmiştir (Çadırcı, 1997: 297, 298). Telgraf hatları kısa süre Osmanlı taşrasında da yayılmıştır. 1881-1882' de Ermenek'te Telgraf memurluğu oluşturulmuştur. Telgraf Memuru Cevad Efendi'dir (AVS, 1299: 79). 1891-1892'de Telgraf ve Posta İdaresi'nde Müdür İzzet Efendi, süvari çavuşu Hidayet Ağa (AVS, 1309: 132), 1894-1895'te Müdür Ahmed Efendi olmuş iken diğer memurlar değişmemiştir (AVS, 1312: 196). 1900-1903'te Posta ve Telgraf müdürü Mehmed Sabri Efendi, Telgraf Çavuşu Hidayet Ağa'dır (AVS, 1318: 217; AVS, 1320: 216). 1906'da telgraf müdürü Nureddin Efendi'dir (KVS, 1322: 82).

Ermenek'te 1890-1891'de banka şubesinin kurulduğu görülmektedir. Bankanın Reisi Hoca zâde Kâmil Efendi, Muhasebe Kâtibi Ahmed Hamdi Efendi, üyeler; Hacı Said Efendi, Hacı Burhan zâde Osman Ağa, Müftü zâde Reşid Efendi, Ziyaeddin zâde Osman Efendi, Eğri Ali zâde Hacı Ali Ağa'dır (AVS, 1308: 123). 18911892 'de banka şubesi reisi Hacı Said Efendi iken üyelerden Eğri Ali zâde Hacı Ali yerine Hacı Mehmed Efendi üye olmuştur (AVS, 1309: 131). 1894-1895'te reis Kâmil Efendi, muhasebe kâtibi Hikmet Bey, üyeler; Nuri Efendi, Müftü zâde Reşid Efendi, Ziyaeddin zâde Osman Efendi ve Osman Ağa'dır (AVS, 1312: 195). 19001903'te Ziraat Bankası'nın Reisi Kâmil Efendi, muhasebe kâtibi Mehmed Nuri Efendi, üye Osman Efendi, Hacı Hâfız Efendi ve Osman Ağa (AVS, 1318: 216; AVS, 1320: 215), 1906'da reis Muhlis Efendi, üyeler; Hacı Metin Ağa zâde Ali Efendi, Numan Efendi zâde Mehmed Efendi, Hacı Hasib Efendi zâde Rüstem Efendi, Muhasebe kâtibi Salih Naci Efendi, muavini Mustafa Behcet Efendi'dir (KVS, 1322: 82).

Tanzimat'la birlikte iç güvenliğin sağlanması amacıyla birtakım düzenlemeler de yapılmıştı 1844 yılı itibarıyla Zaptiye Teşkilatı kurulmuştur. Piyade ve süvari neferleri ile iç güvenliğin teminine çalışılmaktaydı. Taşrada Zaptiye Teşkilatı' nın kısa sürede yaygınlaştığı görülmektedir (Çadırcı, 1997: 318). Ermenek'te 18901891'de güvenlik işleri için zabıta teşkilatı kurulmuştur. 1890-1892'de zabıta teşkilatında Memur Mülazım Hacı Abdullah Ağa, Piyade Çavuş Ahmed ve Mustafa ile 29 nefer görev yapmaktadır (AVS, 1308: 123; AVS, 1309: 132). 1894-1895'te memur vekili Ahmed Çavuş, Piyade Çavuş Mustafa ve 28 nefer görev yapmaktadır (AVS, 1312: 195). 1900-1901'de Zabıta Memuru Yüzbaşı Mustafa Efendi, piyade çavuş Ahmed Ağa'dır (AVS, 
1318: 217). 1902-1903'te piyade Çavuş olarak Hüseyin Ağa görev yaparken Polis memuru olarak Mehmed Emin Efendi yer almaktadır (AVS, 1320: 216). XX. yüzyıl başı itibarıyla Ermenek'te güvenlik işleri için polis teşkilatının da kurulduğu anlaşılmaktadır. 1906'da zabıta memuru Yüzbaşı Ahmed Efendi'dir (KVS, 1322: 82).

\section{Cumhuriyet'in İlk Yıllarında Ermenek'in İdarî Yapısı}

Cumhuriyet döneminde Konya'ya bağlanan Ermenek sınırları içinde 48 köy bulunmaktaydı (Tekindağ, 1978: 317). Cumhuriyet'in ilk yıllarında Konya'ya bağlı bir kaza olan Ermenek'te Fariske ve Davdas olmak üzere iki nahiye ve merkez kaza şeklinde idari yönden taksim olunmuştur (Doktor Nazmi, 1922: 110).

Tablo 3: 1922'de Ermenek'e Bağlı Köyler

\begin{tabular}{|c|c|c|c|c|c|}
\hline Köy Adı & $\begin{array}{l}\text { Bağlı } \\
\text { Olduğu Yer }\end{array}$ & Köy Adı & $\begin{array}{l}\text { Bağlı Olduğu } \\
\text { Yer }\end{array}$ & Köy Adı & $\begin{array}{l}\text { Bağlı Olduğu } \\
\text { Yer }\end{array}$ \\
\hline Bisse & $\begin{array}{l}\text { Merkez } \\
\text { Kaza }\end{array}$ & Yukarı İzvid & $\begin{array}{l}\text { Davdas } \\
\text { Nahiyesi }\end{array}$ & $\begin{array}{l}\text { Küçük } \\
\text { Karapınar }\end{array}$ & $\begin{array}{l}\text { Fariske } \\
\text { Nahiyesi }\end{array}$ \\
\hline Ezvendi & $\begin{array}{l}\text { Merkez } \\
\text { Kaza }\end{array}$ & Aşağı İzvid & $\begin{array}{l}\text { Davdas } \\
\text { Nahiyesi }\end{array}$ & Sarı Veliler & $\begin{array}{l}\text { Fariske } \\
\text { Nahiyesi }\end{array}$ \\
\hline Emes & $\begin{array}{l}\text { Merkez } \\
\text { Kaza }\end{array}$ & Ala Kilise & $\begin{array}{l}\text { Davdas } \\
\text { Nahiyesi }\end{array}$ & Adiller & $\begin{array}{l}\text { Fariske } \\
\text { Nahiyesi }\end{array}$ \\
\hline Mamallar & $\begin{array}{l}\text { Merkez } \\
\text { Kaza }\end{array}$ & Gargara & $\begin{array}{l}\text { Davdas } \\
\text { Nahiyesi }\end{array}$ & Turçalar & $\begin{array}{l}\text { Fariske } \\
\text { Nahiyesi }\end{array}$ \\
\hline Eskice & $\begin{array}{l}\text { Merkez } \\
\text { Kaza }\end{array}$ & Dize Yol & $\begin{array}{l}\text { Davdas } \\
\text { Nahiyesi }\end{array}$ & Civler & $\begin{array}{l}\text { Fariske } \\
\text { Nahiyesi }\end{array}$ \\
\hline Gürs & $\begin{array}{l}\text { Merkez } \\
\text { Kaza }\end{array}$ & Başköy & $\begin{array}{l}\text { Davdas } \\
\text { Nahiyesi }\end{array}$ & Mencek & $\begin{array}{l}\text { Fariske } \\
\text { Nahiyesi }\end{array}$ \\
\hline Çetme & $\begin{array}{l}\text { Merkez } \\
\text { Kaza }\end{array}$ & Lafza & $\begin{array}{l}\text { Davdas } \\
\text { Nahiyesi }\end{array}$ & Uğurlu & $\begin{array}{l}\text { Fariske } \\
\text { Nahiyesi }\end{array}$ \\
\hline Ertüh & $\begin{array}{l}\text { Merkez } \\
\text { Kaza }\end{array}$ & Kışla & $\begin{array}{l}\text { Davdas } \\
\text { Nahiyesi }\end{array}$ & Lamos & $\begin{array}{l}\text { Fariske } \\
\text { Nahiyesi }\end{array}$ \\
\hline Çavuş & $\begin{array}{l}\text { Merkez } \\
\text { Kaza }\end{array}$ & Yeniceköy & $\begin{array}{l}\text { Davdas } \\
\text { Nahiyesi }\end{array}$ & Gönder & $\begin{array}{l}\text { Fariske } \\
\text { Nahiyesi }\end{array}$ \\
\hline Zelve & $\begin{array}{l}\text { Merkez } \\
\text { Kaza }\end{array}$ & Kirve & $\begin{array}{l}\text { Davdas } \\
\text { Nahiyesi }\end{array}$ & Çukur Bağ & $\begin{array}{l}\text { Fariske } \\
\text { Nahiyesi }\end{array}$ \\
\hline Aşağı Erinol & $\begin{array}{l}\text { Merkez } \\
\text { Kaza }\end{array}$ & $\begin{array}{l}\text { Büyük } \\
\text { Karapınar }\end{array}$ & $\begin{array}{l}\text { Davdas } \\
\text { Nahiyesi }\end{array}$ & Taran & $\begin{array}{l}\text { Fariske } \\
\text { Nahiyesi }\end{array}$ \\
\hline
\end{tabular}




\begin{tabular}{|l|l|l|l|l|l|}
\hline Yukarı Erinol & $\begin{array}{l}\text { Merkez } \\
\text { Kaza }\end{array}$ & İzne Yol & $\begin{array}{l}\text { Davdas } \\
\text { Nahiyesi }\end{array}$ & Muti & $\begin{array}{l}\text { Fariske } \\
\text { Nahiyesi }\end{array}$ \\
\hline Kazancı & $\begin{array}{l}\text { Merkez } \\
\text { Kaza }\end{array}$ & Halimiye & $\begin{array}{l}\text { Davdas } \\
\text { Nahiyesi }\end{array}$ & Muzvadi & $\begin{array}{l}\text { Fariske } \\
\text { Nahiyesi }\end{array}$ \\
\hline Akmanastır & $\begin{array}{l}\text { Merkez } \\
\text { Kaza }\end{array}$ & Boyalık & $\begin{array}{l}\text { Davdas } \\
\text { Nahiyesi }\end{array}$ & & \\
\hline Ayrasıllar & $\begin{array}{l}\text { Merkez } \\
\text { Kaza }\end{array}$ & Çene & $\begin{array}{l}\text { Davdas } \\
\text { Nahiyesi }\end{array}$ & & \\
\hline Sarı Vadi & $\begin{array}{l}\text { Merkez } \\
\text { Kaza }\end{array}$ & Gözde & $\begin{array}{l}\text { Davdas } \\
\text { Nahiyesi }\end{array}$ & & \\
\hline Toplam & 16 köy & Toplam & $\begin{array}{l}\text { Davdas } \\
\text { Nahiyesi }\end{array}$ & & 13 köy \\
\hline
\end{tabular}

Ermenek merkez ile iki nahiyesinde 1922'de 46 köy bulunmaktadır. Cumhuriyet'in ilk yıllarında Ermenek'e bağlı köy sayısında çok fazla değişiklik olmadığı görülmektedir. Nitekim, Konya Vilayeti'ne bağlı olan Ermenek Kazası'na 1928'de iki nahiye ve 46 köy bağlıdır (Dahiliye Vekaleti, 1928: 10). 1928'de Merkez nahiyesinde 16 köy varken Ermenek'te 15 mahalle, Halimiye -Davdas nahiyesinde 16, Fariske nahiyesinde 14 köy bulunmaktadır. Davdas Nahiyesi adı yerine Halimiye adının da kullanıldığı görülmektedir. Nitekim Davdas ve Halimiye köyleri bu nahiye sınırları içindedir.

Ermenek Merkez Nahiyesi'nde 1928'de; Artova, Aşağı İrenbol, Akmanastır, Ezvendi, Eskice, Emsi, Balgasun, Bisse, Çemene, Çavuş, Zeyve, Sarı Vadi, Kazancı, Körmel, Mihallar ve Yukarı İrenbol köyleri yer almaktaydı. Halimiye Nahiyesi'nde; Aşağı İzvid, Ala Kilise, İznebol, Başköy, Büyük Karapınar, Çine, Halimiye, Davdas, Dindebol, Gargara, Kışla, Kerde, Kuzve, Lafza, Nadire ve Yukarı İzvid köyleri bulunmaktaydı. Fariske Nahiyesi sınırları içinde Uğurlu, Boyalık, Cıvlar, Çukurbağ, Sarı Veliler, Turcalar, Adiller, Fariske, Künder, Küçük Karapınar, Lamos, Mencek, Molumu ve Muzvadi köyleri mevcuttu (Dahiliye Vekaleti, 1928: 833-834). Fariske Nahiyesi'nin adı sonraki dönemlerde Göktepe olmuş buraya 1960'ı yıllarda 14 köy bağlanmıştır. Halimiye Nahiyesi'nin adı Tepebaşı olarak değiştirilmiş buraya 11 köy bağlanmıştır. 1960'larda Kazancı adlı nahiyeye ise dokuz köy bağlı olup, Ermenek merkeze ise 15 köy bağlıdır (Akandere, 2016: 315). Cumhuriyet döneminde 1933'te çıkarılan bir kanunla İçel ve Mersin vilayetleri birleştirilerek merkezi Mersin olmak üzere İçel vilayeti oluşturulmuştur (Gazel, 2016: 228). 1933'te yapılan idari düzenlemede Mersin ile içel'in birleştirilmesi esnasında Ermenek, İ̧̧el'den ayrılarak Konya Vilayeti'ne bağlanmıştır (Sarıköse, 2013: 114).

Köylerin isimlerinin değiştirilmesi sürecinin Ermenek'te de yaşandığı anlaşılmaktadır. Ermenek'e bağlı; Arnaval Köyü’nün adı Yalındal, Balkusun Köyü'nün adı Bağbelen, Bise Köyü’nün adı Evsin, Çimene Köyü’nün adı Ağaççatı, Ezvendi Köyü’nün adı Kayaönü, Görmel Köyü’nün adı Üçbölük, İmsi Köyü’nün adı Gökçeeski, Karkara Köyü’nün adı Güneyyurt, Muhallar Köyü’nün adı Çamlıca, Aşağıizvit Köyü’nün adı Aşağı Çağlar, Kopukoğlu Köyü'nün adı ise Olukpınar olarak değiştirilmiştir (Akandere, 2016: 320). 1933'ten itibaren Ermenek kesin olarak Konya Vilayeti'ne bağlanmıştır. 1990'lı yıllarda Karaman, Konya'dan ayrılarak müstakil bir vilayet haline dönüşünce Ermenek de yeni kurulan Karaman Vilayeti'ne bağlanmıştır. Ermenek günümüzde Karaman Vilayeti'nin bir ilçesi konumundadır. 


\section{Sonuç}

Konya ve çevresinin kesin olarak Osmanlı idaresine girmesinden sonra Ermenek de Osmanlı sınırları içine dahil olmuştur. Osmanlı idaresine girdikten sonra Karaman Eyaleti İç-il Livası sınırları içinde olan Ermenek'in idari tarihi XX. yüzyıl başlarına kadar bu liva ile beraber şekillenmiştir. Kıbrıs'ın 1571'de fethinden sonra bir süre İç-il Livası sınırları içinde bulunduğundan dolayı Kıbrıs'a bağlanan Ermenek, daha sonra Iç̧-il Livası́nın Adana Vilayeti'ne bağlanmasından sonra Adana Vilayeti sınırları içine dahil olmuştur. İç-il Livası'nın merkezi olan Ermenek'in İç-il Livası'nın merkezinin Silifke'ye taşınmasından sonra idari yönden tekrar liva merkezi olarak Konya Vilayeti'ne bağlanma girişimleri olmuş ancak bu girişimler sonuçsuz kalmıştır. Kısa süreli Konya Vilayeti'ne bağlı olan Ermenek genel olarak Adana Vilayeti sınırları içinde kalmıştır. Ermenek, XX. yüzyıl başında Cumhuriyet'in ilk yıllarından itibaren ise Konya Vilayeti'ne bağlanmış. 1990'lı yıllarda Karaman Vilayeti'nin kurulmasından sonra ise Karaman Vilayeti'nin bir kazası haline gelmiştir.

Ermenek'in idari yapısında Osmanlı Devleti'nin XIX. yüzyıl sonlarındaki 1864 ve 1871 Vilayet Nizamnameleri'ne göre yeni idari birimler oluşturulmuştur. Kaza idaresinde kaza idare meclisi, belediye dairesi gibi temel idari birimler yanında bidayet ve ticaret mahkemeleri, nüfus ve tapu idaresi, zabıta ve mal kalemi gibi dairelerin kurulması Ermenek'in bürokratik yapısının şekillenmesine katkı sağlamıştır. Osmanlı döneminde Ermenek genel itibarıyla dağlık bir araziye sahip olup, tarım ve hayvancılığa dayalı bir ekonomik yapıya sahipti. Ermenek'te XIX. yüzyıl sonunda birçok idari birim ve memuriyetin tesis edilmesi Ermenek'in ekonomik yapısına da olumlu yönde katkı sağlamıştır. Ayrıca Ermenek'te kurulan her yeni idarî birim ve memuriyet Ermenek'in XIX. yüzyıl sonlarında sosyal hayatının gelişmesine de büyük katkı sağlamıştır.

\section{Kaynakça / References}

Adana Vilâyet Salnâmesi, (AVS), 1289, 1290, 1293, 1294, 1296, 1297, 1299, 1308, 1309, 1312, 1318, 1320.

Akandere, Osman (2016). Osmanlı Devleti'nden Türkiye Cumhuriyeti'ne Konya. Konya: Eğitim Yayınevi.

Aköz, Alaaddin \& Bayram Ürekli (2006). "Karamanoğullarından Osmanlıya Konya”. Konya Ticaret Odası Yeni ipek Yolu Konya Kitabı, IX, (Ed.: Haşim Karpuz- Osman Eravşar), Konya: Inci Ofset, s. 77-115.

Başbakanlık Osmanlı Arşivi (BOA), (1996). 387 Numaralı Muhâsebe-i Vilâyet-i Karaman ve Rûm Defteri (937/1530), Konya, Bey-şehri, Ak-şehir, Larende, Ak-saray, Niğde, Kayseriyye ve iç-il Livâları, Ankara: Başbakanlık Osmanlı Arşivi Yay.

Bilgili, Ali Sinan (2001). Osmanlı Döneminde Tarsus Sancağı ve Tarsus Türkmenleri, Ankara: Kültür Bakanlığı Yay.

Çadırcı, Musa (1997). Tanzimat Döneminde Anadolu Kentleri'nin Sosyal ve Ekonomik Yapısı. Ankara: TTK.

Çelik, Şenol (2000). "içel”. Türkiye Diyanet Vakfı İslâm Ansiklopedisi, C. 21, İstanbul: Türkiye Diyanet Vakfı Yay., s. 450-455.

Dahiliye Vekâleti (1928). Son Teşkilat-ı Mülkiyede Köylerimizin Adları. İstanbul: Hilal Matbaası.

Doktor Nazmi (1922). Türkiye’nin Sıhhi-i íctimâi Coğrafyası Konya Vilayeti, Ankara: Öğüd Matbaası. 
Gazel, Ahmet Ali (2016). “içel Sancă̆ı́nın Sancak Merkezi Olmak İçin Ermenek ve Silifkelilerin Yaptıkları Mücadele". Tarihte Adana ve Çukurova, Uluslararası "Tarihte Adana ve Çukurova Sempozyumu Bildirileri Kitabı (17-19 Nisan 2015), C. III, Adana: Akademisyen Kitabevi, s. 225-264.

Karpat, Kemal H. (2003). Osmanlı Nüfusu (1830-1914) Demografik ve Sosyal Özellikleri, (Çev.: Bahar Tırnakcı), İstanbul: Tarih Vakfı Yurt Yay.

Kılıç, Orhan (1999). "XVII. Yüzyııın İlk Yarısında Osmanlı Devleti'nin Eyalet ve Sancak Teşkilatlanması". Osmanlı, C.VI, Ankara: Yeni Türkiye Yay., s. 89-110.

Konya Vilayet Salnamesi, (KVS), 1322, 1332.

Konyalı, İbrahim Hakkı (1997). Âbideleri ve Kitabeleri ile Konya Tarihi. Konya: Burak Matbaası.

Ortaylı, Illber (2000). Tanzimat Devrinde Osmanlı Mahalî Idareleri (1840-1880). Ankara: TTK.

Sarıköse, Barış (2013). "Konya Vilâyet Salnâmelerine Göre iç-il Livası". Türk-islâm Medeniyeti Akademik Araştırmalar Dergisi, S. 15, s. 113-127.

Sarıköse, Barış (2016). "Adana Vilayet Salnâmelerine Göre XIX. Yüzyıl Sonlarında Adana'nın İdari Yapısı". Tarihte Adana ve Çukurova, Uluslararası "Tarihte Adana ve Çukurova Sempozyumu Bildirileri Kitabı (17-19 Nisan 2015), C. III, Adana: Akademisyen Kitabevi, s. 553-573.

Tekindağ, M. C. Şihâbeddin (1978). “Ermenek”. İs/âm Ansiklopedisi, C. IV, İstanbul: MEB, s. 316-317.

Turan, Osman (1998). Selçuklular Zamanında Türkiye Siyasî Tarih Alp Arslan'dan Osman Gazi'ye (10711328). İstanbul: Boğaziçi Yay.

Uzunçarşılı, İsmail Hakkı (1998). Osmanlı Tarihi, C.I, Anakara: TTK. 